\title{
Hydrological Modelling of the Mono River Basin at Athiémé
}

\author{
Eliézer Iboukoun Biao ${ }^{1,4}$, Ezéchiel Obada ${ }^{1,4}$, Eric Adéchina Alamou ${ }^{1,4}$, Josué Esdras Zandagba ${ }^{1}$, \\ Amédée Chabi $^{1}$, Ernest Amoussou ${ }^{2}$, Julien Adounkpe ${ }^{3}$, and Abel Afouda ${ }^{1,3}$ \\ ${ }^{1}$ Laboratory of Applied Hydrology (LHA), University of Abomey-Calavi, 01 BP 4521, Abomey-Calavi, Benin \\ ${ }^{2}$ Laboratoire Pierre PAGNEY, Climat, Eau, Ecosystème et Développement (LACEEDE), \\ University of Abomey-Calavi, Abomey-Calavi, Benin \\ ${ }^{3}$ West African Science Service Center on Climate Change and Adapted Land Use, \\ GRP Water Resources, University of Abomey-Calavi, Abomey-Calavi, Benin \\ ${ }^{4}$ Laboratoire de Géosciences, de l'Environnement et Applications (LaGEA), National University of Sciences, \\ Technology, Engineering and Mathematics, Abomey, Benin
}

Correspondence: Eliézer Iboukoun Biao (biaoeliezer@yahoo.fr)

Published: 16 November 2021

\begin{abstract}
The objective of this study is to model the Mono River basin at Athiémé using stochastic approach for a better knowledge of the hydrological functioning of the basin. Data used in this study consist of observed precipitation and temperature data over the period 1961-2012 and future projection data from two regional climate models (HIRHAM5 and REMO) over the period 2016-2100. Simulation of the river discharge was made using ModHyPMA, GR4J, HBV, AWBM models and uncertainties analysis were performed by a stochastic approach. Results showed that the different rainfall-runoff models used reproduce well the observed hydrographs. However, the multi-modelling approach has improved the performance of the individual models. The Hermite orthogonal polynomials of order 4 are well suited for the prediction of flood flows in this basin. This stochastic modeling approach allowed us to deduce that extreme events would therefore increase in the middle of the century under RCP8.5 scenario and towards the end of the century under RCP4.5 scenario.
\end{abstract}

\section{Introduction}

Water resource management and catchment analysis are crucial aspects of the twenty-first century in hydrological and environmental sciences (Chalkias et al., 2016). Benin Republic has an aquatic ecosystem, supplied and varied, represented from downstream to upstream by a significant maritime component, a system of lagoons and lakes and a hydrographic network in which fit the Lake Ahémé and its channels (Amoussou, 2010). This hydrographic basin - lagoon - lake and maritime system continuum is very sensitive to climate forcing. Nowadays, the lake Ahémé is facing a real problem of sedimentation. The Mono River is one of the main water inlets of this lake. Several hydrological studies have already been conducted in the Mono River basin (Amoussou et al., 2014; Lawin et al., 2019; Koubodana et al., 2019; Amoussou et al., 2020). However, none of these studies have investigated the multi-modelling approach, as well as performing uncertainty analysis using stochastic approach. The objective of this study is therefore to model the Mono River basin at Athiémé using stochastic approach for a better knowledge of the hydrological functioning of the basin.

\section{Materials and methods}

\subsection{Study area}

The Mono River basin at Athiémé occupies an area of $21500 \mathrm{~km}^{2}$ shared between two West-African countries, Togo and Benin. Specifically, it is located between the latitudes $06^{\circ} 16^{\prime}$ and $09^{\circ} 20^{\prime} \mathrm{N}$, and the longitudes $0^{\circ} 42^{\prime}$ and $2^{\circ} 25^{\prime} \mathrm{E}$ (Fig. 1). It hosts the Nangbéto hydropower dam built in 1987 and utilized by the two countries. The river serves as 


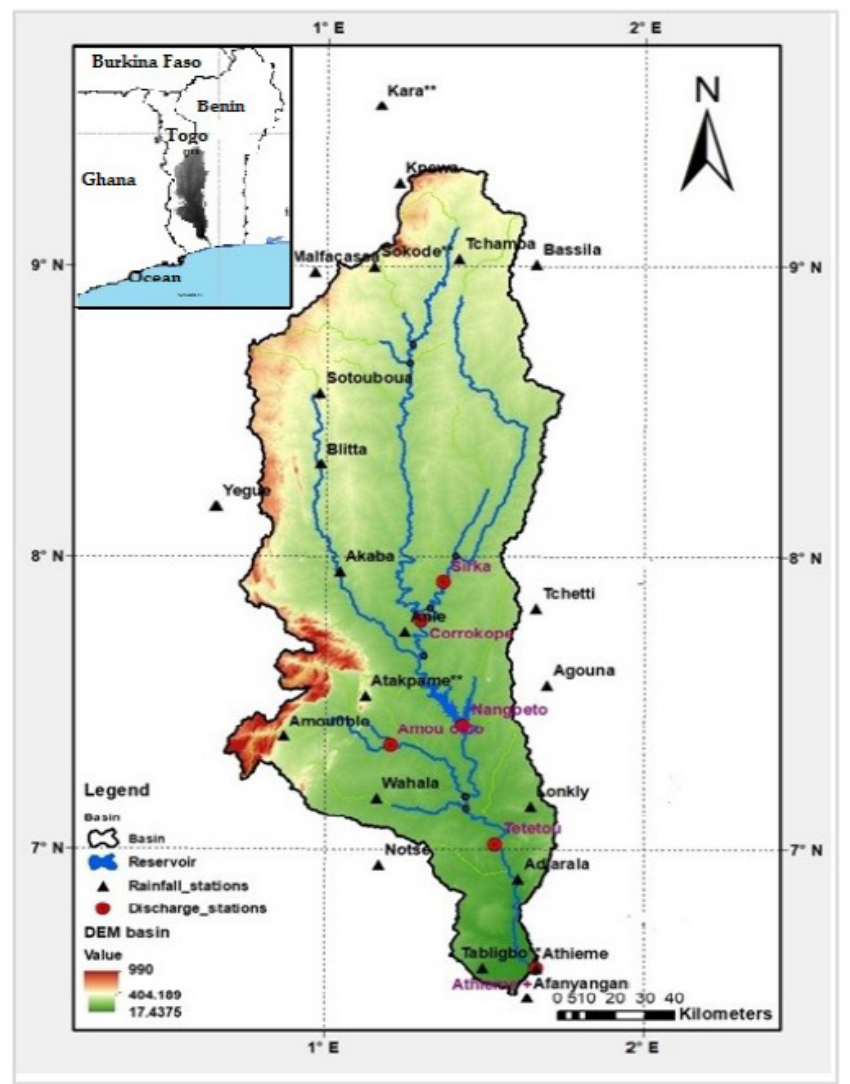

Figure 1. Study area.

natural border between the two countries in the southern part. The climate is tropical (two rainy seasons and two dry seasons) downstream and subequatorial (one rainy season and one dry season) upstream (Lawin et al., 2019). This river basin is patterned in the south by floodplains and plateaus, and higher landforms in the north and north-west, e.g., the Atakora Mountains with a height of $800 \mathrm{~m}$ and their southern extensions that are the Togo mountains (Amoussou et al., 2020).

\subsection{Methods}

\subsubsection{Observed and Regional Climate Models (RCM) data used}

Observed meteorological data (daily rainfall data, temperature data) and daily discharge data were provided, respectively, by the Benin Meteorological Department, i.e., MétéoBenin and the National Directorate of Water (DG-Eau). The observed data are considered for the period 1961-2012 (good compromise, taking into account the length of the data available in the different stations). The historical and future projections (RCP4.5 and RCP8.5 scenarios) rainfall data of two RCM (HIRHAM5 and REMO) were obtained from CORDEX Africa project (http://www.cordex.org, last access: 3 December 2020). These two RCM were chosen to test their ability to reproduce the observed rainfall data in Mono catchment for impact studies. The reference period selected for examining the rainfall bias was the period 19612005. For future projections, the RCP4.5 and RCP8.5 scenarios are considered over the period 2016 à 2100.

\subsubsection{Data processing}

Preprocessing of hydro-climatic data: This involves reconstructing the missing hydro-climatic data and carrying out the spatialisation by using the ordinary kriging method.

Bias correction: ISI-MIP method (Hempel et al., 2013) was used for the correction of bias contained in the temperature and rainfall data from the investigated RCM.

Calculation of Potential Evapotranspiration (PET): The calculation of daily PET by the formula of Oudin et al. (2005), which only uses as input the temperature, was retained for hydrological modeling. This ETP formula is simple and efficient and allows to obtain better results in terms of flow simulation.

Hydrological modelling: In this study, several hydrological models were used: ModHyPMA, GR4J, HBV and AWBM (Table 1). These models have been used successfully in previous studies (Alamou et al., 2010; Amoussou, 2010; Amoussou, 2015; Biao et al., 2016). They will be calibrated over the period 1961-1965 and validated, firstly, over the period 1971-1975 (period before the establishment of the Nangbéto dam) and secondly over the period 1988-1992 (period after the establishment of the dam in 1987). This was done in order to consider the effect of the operation of the dam on the flow simulations at the Athiémé outlet. Ensembles of these models were also considered because the average of the outputs of the different models could also reduce the uncertainties related to the models structure. In order to evaluate the model performance for the calibration and validation, the coefficient of model efficiency CE (Nash and Sutcliffe, 1970) and the coefficient of determination $R^{2}$ were used.

Uncertainty analysis: stochastic modeling of flood flows: Hydrological processes are natural phenomena having not only a dynamic aspect but also a stochastic character. Thus, any analysis of hydrological data should seek to take into account both stochastic and dynamic aspects. In addition, precipitation at the entrance to the basin is the result of complex physical phenomena that give it a stochastic behavior. The stochastic formulation of ModHyPMA by methods based on the use of stochastic differential equations (SDE) allows to better take into account the uncertainties in the rainfallrunoff modeling. The SDE that describes the Mono basin at Athiémé can be written in the form of Eq. (1) (Alamou, 2011; Biao et al., 2016):

$\mathrm{d} Q(t)=f(Q, t) \mathrm{d} t+G(Q, t) \mathrm{d} W(t)$ 
Table 1. Characteristics of the rainfall-runoff models used.

\begin{tabular}{llrrll}
\hline Models & Structure & Parameters & Reservoirs & Input & References \\
\hline ModHyPMA & Physically & 2 & & $P$, PET $+Q$ & Afouda et al. (2010) \\
GR4J & Conceptual & 4 & 2 & $P$, PET $+Q$ & Edijatno Nascimento et al. (1999) \\
HBV & Conceptual & 9 & 3 & $P$, PET $+Q$ & Bergström (1973) \\
AWBM & Conceptual & 7 & 3 & $P$, PET $+Q$ & Boughton (1993) \\
\hline
\end{tabular}

where $[\mathrm{d} W(t), t \in T]$ is a Brownian motion process. One of the advantages of SDE is the use that can be made of its associated Fokker-Planck equation (FPE). The FPE is a general probabilistic approach to describe the dynamics of various stochastic systems. It models the time evolution of the probability distribution in a system under uncertainty. It can be written in the form of Eq. (2):

$$
\begin{aligned}
\frac{\partial P(Q, t)}{\partial t} & =-\frac{\partial}{\partial Q}[f(Q, t) P(Q, t)] \\
& +\frac{1}{2} \frac{\partial^{2}}{\partial Q^{2}}\left[2 G^{2}(Q, t) P(Q, t)\right]
\end{aligned}
$$

where $f(Q, t)$ et $2 G^{2}(Q, t)$ represent respectively the mean and the variance. Hermite polynomial expansion to approximate probability distribution of flood flows (Afouda and Alamou, 2010; Alamou, 2011; Biao et al., 2016) is given in the form of Eq. (3):

$$
P(u, t)=\frac{1}{\sqrt{2 \pi}} e^{-\frac{u^{2}}{2}}\left[1+\sum_{i=1}^{n} A_{i} H_{i+1}(u)\right]
$$

where $\quad A_{1}=0 ; A_{2}=\frac{\mu_{3}}{3 !} ; \quad A_{3}=\frac{\mu_{4}-3}{4 !} ; \quad$ etc.; $\quad H_{n}(u)=$ $(-1)^{n} e^{\frac{u^{2}}{2}} \frac{d^{n}}{\mathrm{~d} u^{n}}\left(e^{-\frac{u^{2}}{2}}\right) ; u=\frac{Q-E[Q]}{\sigma_{Q}}$ and $\mu$ represent the centered moments of the variable $u$. Based on the above expressions of the expansion coefficients, the time series of the observed or simulated maximum daily mean flows are used to make calculations of $P(u, t)$ for the first four orders. From this approximation of probability distribution of flood flows, the values of the 2, 5, 10, 20, 50 and 100 years return period were determined.

\section{Results and discussion}

\subsection{Hydrological modelling}

Figures 2 and 3 and Table 2 show the results of the rainfallrunoff simulation in the Mono river basin at Athiémé. A closer look at Figs. 2 and 3 reveals an underestimation of flood peaks by the different models. This confirms the regulatory role of dams in accordance with the conclusions of Payan (2007). In addition, the multi-model approach has improved the performance of individual models. Indeed, the performance in calibration, in validation 1 and in validation 2 of the ensemble of HBV, ModHyPMA and GR4J, as well as

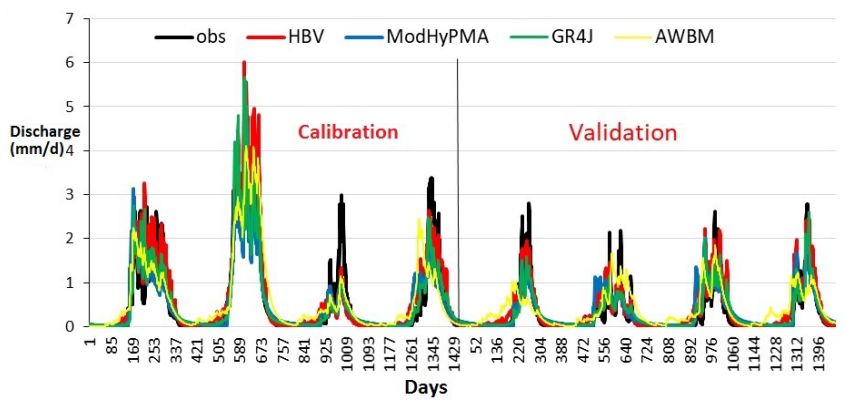

Figure 2. Calibration and validation of the investigated models in the Mono basin at Athiémé.

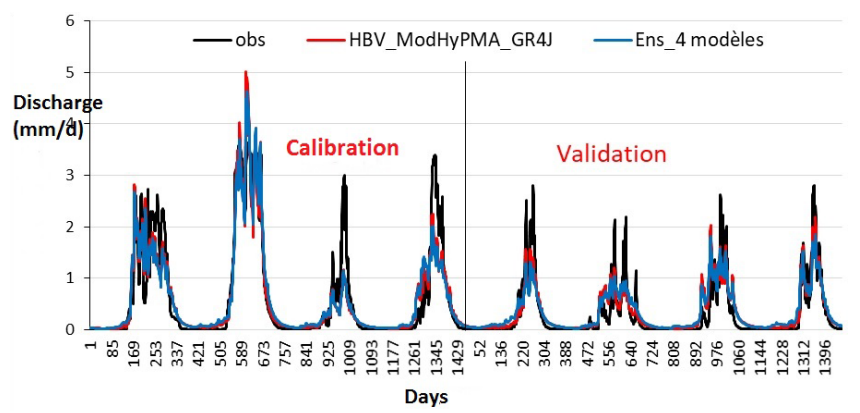

Figure 3. Calibration and validation of the investigated ensemble models in the Mono basin at Athiémé.

the ensemble of the 4 rainfall-runoff models are better than the performance of the models taken individually. However, the validation of the models after the impoundment of the dam is less good than the first validation. This can be explained by the influence of the water releases at the dam.

In order to better take into account the uncertainties, stochastic modeling of flood flows in the Mono basin at Athiémé is crucial.

\subsection{Stochastic modelling of flood flows}

Figure 4 shows the results of the fitting of the simulated flood flows with approximations based on Hermite orthogonal polynomials. From this figure, it can be deduced that it is the probability distribution based on the Hermite orthogonal polynomials of order 4 which best fits the observation data and those simulated in the Mono basin at Athiémé. 
Table 2. Performance of the rainfall-runoff.

\begin{tabular}{lrrr|rrr|rrr}
\hline & \multicolumn{3}{c}{ Calibration } & \multicolumn{3}{c}{ Validation_1 } & \multicolumn{3}{c}{ Validation_2 } \\
\cline { 2 - 9 } Model & Nashroot & Nash & $R^{2}$ & Nashroot & Nash & $R^{2}$ & Nashroot & Nash & $R^{2}$ \\
\hline HBV & 0.87 & 0.78 & 0.82 & 0.80 & 0.79 & 0.80 & 0.21 & 0.41 & 0.64 \\
ModHyPMA & 0.83 & 0.75 & 0.79 & 0.72 & 0.70 & 0.71 & 0.51 & 0.50 & 0.55 \\
GR4J & 0.87 & 0.78 & 0.79 & 0.82 & 0.81 & 0.83 & 0.51 & 0.49 & 0.62 \\
AWBM & 0.75 & 0.72 & 0.72 & 0.37 & 0.36 & 0.41 & 0.48 & 0.61 & 0.64 \\
Ens_HBV_ModHyPMA_GR4J & 0.88 & 0.82 & 0.83 & 0.81 & 0.79 & 0.81 & 0.52 & 0.55 & 0.64 \\
Ens_of 4_models & 0.86 & 0.82 & 0.82 & 0.74 & 0.75 & 0.78 & 0.55 & 0.58 & 0.65 \\
\hline
\end{tabular}
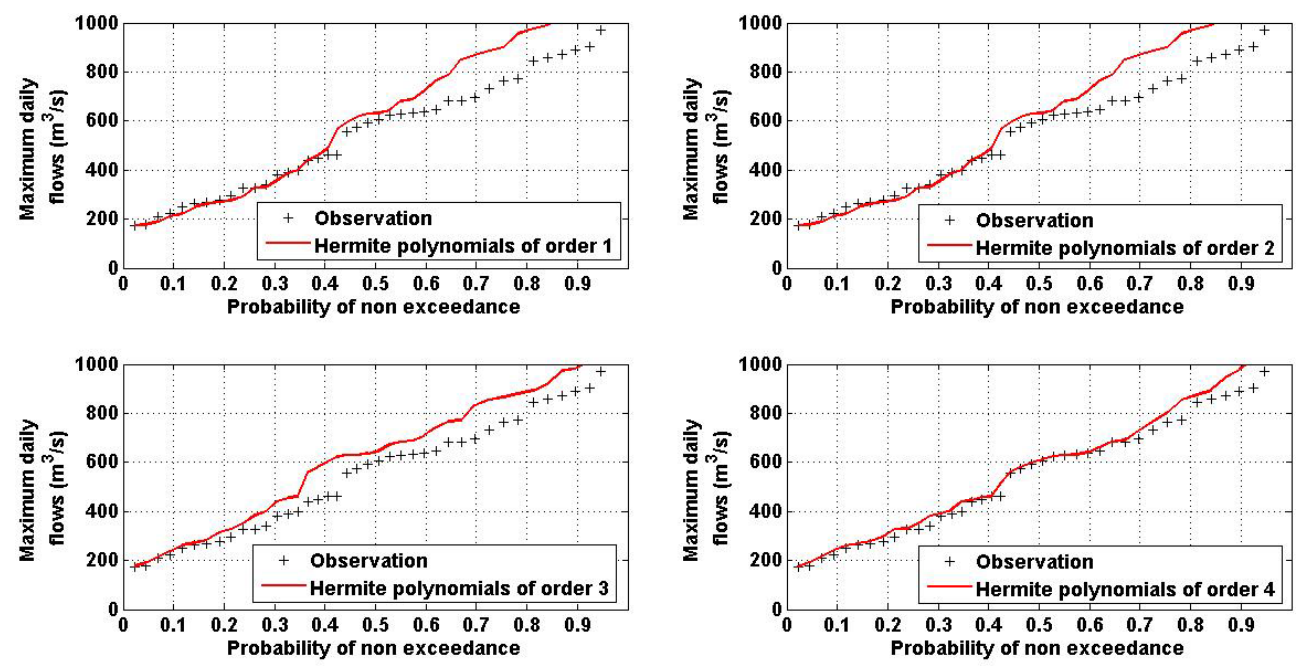

Figure 4. Fitting curve of the probability distribution based on Hermite polynomials for the simulated maximum daily flows in the Mono basin at Athiémé.

The results also showed that the simulated maximum flows, using the observed rainfall data in the basin, are underestimated for the 2 and 5 years return periods, whereas these flows are overestimated for the 100 years return period, in comparison with the observed maximum flows. However, using historical data from the REMO and from the ensemble REMO and HIRHAM5, the relative differences between the values of the simulated flows and those of observed flows are not too high, compared to those obtained with HIRHAM5 alone. These differences vary from $18 \%$ (for $T=100$ years return period) to $21 \%$ (for $T=2$ years return period). Therefore, REMO and the ensemble REMO and HIRHAM5 can be used for long-term simulations.

\subsection{Frequency analysis of projected flows}

The results obtained from the REMO climate model project a decrease change of flood flows, under the two RCP4.5 and RCP8.5 scenarios. However, the ensemble HIRHAM5 and REMO project an increase change for the 5, 10, 20, 50 and 100 years return periods in the Mono basin at Athiémé under the two scenarios. In comparison with the observed maximum flows, an increase ranging between $22 \%$ (for $T=$
5 years return period) and $24 \%$ (for $T=100$ years return period) could be obtained. These results allow us to deduce that the extreme events could therefore increase in the middle of the century under RCP8.5 scenario and towards the end of the century under RCP4.5 scenario.

The traditional approach for assessing the probability of outflow of a given frequency has been to pick a storm pattern, choose a runoff model and set the parameters with the best available estimate (for example in Amoussou, 2015). However, one of the most important advantages of the SDE is the associated FPE, which allows one to directly derive the time-varying probabilities associated with the outflow. The stochastic approach used in the present study enables us to take into account both the stochastic and dynamic aspects of the hydrological phenomenon.

\section{Conclusions}

The main contribution of this paper was to model the Mono River basin at Athiémé using stochastic approach for a better knowledge of the hydrological functioning of the basin. The different hydrological models used in this study repro- 
duce well the observed hydrographs in the Mono basin at Athiémé. However, the multi-model approach has improved the performance of the individual models. Stochastic modeling of flood flows shows that the intensity and frequency of flows are likely to be more pronounced under RCP4.5 and RCP8.5 scenarios. The study concluded that climate change will modify the level of floods in the Mono basin at Athiémé. The main advantage of the SDE approach is that it provides a physically transparent and mathematically tractable description of the stochastic dynamics, indicating how uncertainty in input precipitation and environmental parameters (potential evapotranspiration, temperature) affects the uncertainty in model output. Although the use of the SDE and the associated FPE as proposed in this paper can become more complex, the potential benefits in the areas of decision making, data collection and value of information are of promising importance.

Code availability. The code supporting the findings of this study is available from the corresponding author on request.

Data availability. The data supporting the findings of this study are available from the corresponding author on request.

Author contributions. EIB, EO, JEZ, and AC designed the methodological framework and contributed to the entire strategic and conceptual framework of the study. EIB performed the simulations, analyzed the results and prepared the manuscript under the supervision of EAA, EA, JA, and AA.

Competing interests. The contact author has declared that neither they nor their co-authors have any competing interests.

Disclaimer. Publisher's note: Copernicus Publications remains neutral with regard to jurisdictional claims in published maps and institutional affiliations.

Special issue statement. This article is part of the special issue "Hydrology of Large River Basins of Africa". It is a result of the 4th International Conference on the "Hydrology of the Great Rivers of Africa", Cotonou, Benin, 13-20 November 2021.

\section{References}

Afouda, A. and Alamou, E.: Modèle Hydrologique basé sur le Principe de moindre action (MODHYPMA), Annales des Sciences Agronomiques du Bénin, 13, 23-45, 2010.

Alamou, E.: Application du principe de moindre action a la modélisation pluie - débit, Thèse de Doctorat, CIPMA - chaire UNESCO, Université d' Abomey - Calavi, 231 pp., 2011.
Amoussou, E.: Variabilité pluviométrique et dynamique hydrosédimentaire du bassin- versant du complexe fluvio-lagunaire Mono-Ahémé-Couffo (Afrique de l'Ouest), Thèse de Doctorat unique, Université de Bourgogne, Dijon, CRC - CNRS UMR5210, 313 pp., 2010.

Amoussou, E.: Analyse hydrométéorologique des crues dans le bassin-versant du Mono en Afrique de l'Ouest avec un modèle conceptuel pluie-débit, FMSH-WP-2015-90, April 2015.

Amoussou, E., Tramblay, Y., Totin, H. S. V., Mahé, G., and Camberlin, P.: Dynamique et modélisation des crues dans le bassin du Mono à Nangbéto (Togo/Bénin), Hydrol. Sci. J., 59, 2060-2071, https://doi.org/10.1080/02626667.2013.87101, 2014.

Amoussou, E., Awoye, H., Henri S. Vodounon, T., Obahoundje, S., Camberlin, P., Diedhiou, A., Kouadio, K., Mahé, G., Houndénou, C., and Boko, M.: Climate and Extreme Rainfall Events in the Mono River Basin (West Africa): Investigating Future Changes with Regional Climate Models, Water, 12, 833 pp., https://doi.org/10.3390/w12030833, 2020.

Bergström, S. and Forsman, A.: Development of a conceptual deterministic rainfall-runoff model, Nord. Hydrol., 14, 147-170, 1973.

Biao, I. E., Alamou, A. E., and Afouda, A.: Improving rainfallrunoff modelling through the control of uncertainties under increasing climate variability in the Oueme River basin (Benin, West Africa), Hydrol. Sci. J., 61, 2902-2915, 2016.

Boughton, W. C.: A hydrograph-based model for estimating the water yield of ungauged catchments. In: Proceedings of the 1993 Hydrology and Water Resources Conference, Institution of Engineers, Australia, National Conference Publication no. 93, 317324, 1993.

Chalkias, C., Stathopoulos, N., Kalogeropoulos, K., and Karymbalis, E.: Applied Hydrological Modeling with the Use of Geoinformatics: Theory and Practice, Empirical Modeling and Its Applications, Mamun Habib, IntechOpen, https://doi.org/10.5772/62824, 2016.

Edijatno Nascimento, N. O., Yang, X., Makhlouf, Z., and Michel, C.: GR3J: a daily watershed model with three free parameters, Hydrol. Sci. J., 44, 263-277, 1999.

Hempel, S., Frieler, K., Warszawski, L., Schewe, J., and Piontek, F.: A trend-preserving bias correction - the ISI-MIP approach, Earth Syst. Dynam., 4, 219-236, https://doi.org/10.5194/esd-4219-2013, 2013.

Koubodana, H. D., Diekkrüger, B., Näschen, K., Adounkpe, J., and Atchonouglo, K.: Impact of the Accuracy of Land Cover Data sets on the Accuracy of Land Cover Change Scenarios in the Mono River Basin, Togo, West Africa, Int. J. Adv. Remote Sens. GIS, 8, 3073-3095, 2019.

Lawin, A. E., Hounguè, N. R., Biaou, C. A., and Badou, D. F.: Statistical Analysis of Recent and Future Rainfall and Temperature Variability in the Mono River Watershed (Benin, Togo), Climate, 7, 1, https://doi.org/10.3390/cli7010008, 2019.

Nash, J. E. and Sutcliffe, J. V.: River flow forecasting through conceptual models: Part I - A discussion of principles, J. Hydrol., 10, 282-290, https://doi.org/10.1016/0022-1694(70)90255-6, 1970.

Oudin, L., Hervieu, F., Michel, C., Perrin, C., Andréassian, V., Anctil, F., and Loumagne, C.: Which potential evapotranspiration input for a lumped rainfall-runoff model?: Part 2 Towards a simple and efficient potential evapotranspiration 
model for rainfall-runoff modelling, J. Hydrol., 303, 290-306, https://doi.org/10.1016/j.jhydrol.2004.08.026, 2005.
Payan, J.-L.: Prise en compte de barrages-réservoirs dans un modèle global pluie-débit, Thèse de Doctorat de L'ENGREF, CEMAGREF, ANTONY, Paris, 257 pp., 2007. 